\title{
eHealth Literacy and General Interest in Using Online Health Information: A Survey Among Patients with Dental Diseases
}

\author{
Saeideh Valizadeh-Haghi ${ }^{1}$, Shahabedin Rahmatizadeh ${ }^{2 *}$
}

1. Department of Medical Library and Information Sciences, School of Allied Medical Sciences, Shahid Beheshti University of Medical Sciences, Tehran, Iran

2. Department of Health Information Technology and Management, School of Allied Medical Sciences, Shahid Beheshti University of Medical Sciences, Tehran, Iran

\begin{abstract}
:
Objectives: The aim of the study is to explore the eHealth literacy and general interest in using eHealth information among patients with dental diseases.

Methods: A total of 171 patients with dental diseases completed the survey including the eHEALS. The effect of participants' age, gender and education on eHealth literacy was assessed. Spearman's correlation coefficient was also used to assess the correlation between the importance of access to health information and the usefulness of the internet for decision-making.

Results: The mean score of eHealth literacy in the participants was 30.55 (SD=4.069). The participants' age has significant effect on eHealth literacy level ( $t=3.573, P$-value $=0.002)$. Moreover, there was a significant correlation between the total score of eHealth literacy and the importance of access to eHealth information $(r=0.33, n=171, P<0 . s 001)$. The difference in eHealth literacy in terms of educational background showed no statistically significant differences $(F=1.179, P$-value $=0.322)$.

Discussion: the participants had a high level of eHealth literacy. Determining eHealth literacy among dental patients leads to a better understanding of their problems in health decision-making.

Conclusion: Dental institutions efforts should aim to raise awareness on online health information quality and to encourage patients to use evaluation tools, especially among low electronic health literate patients.
\end{abstract}

Keywords: eHealth literacy; eHEALS; dentistry; online health information; consumer health information; patient education

Abbreviations: electronic health(eHealth)

*Correspondence: Shahabedin Rahmatizadeh, email: shahab.rahmatizadeh@gmail.com

DOI: 10.5210/ojphi.v10i3.9487

Copyright @2018 the author(s)

This is an Open Access article. Authors own copyright of their articles appearing in the Online Journal of Public Health Informatics. Readers may copy articles without permission of the copyright owner(s), as long as the author and OJPHI are acknowledged in the copy and the copy is used for educational, not-for-profit purposes. 


\section{Introduction}

The internet is regarded as an important resource for obtaining health information (1) and a valuable tool that assists in dealing with all health concerns (2). The World Wide Web and other technology-based applications have turned into a routine part of health care and public health settings (3), and rather than consulting with health professionals, people are increasingly using these tools as their main resource for seeking information and accessing medical advice $(1,4,5)$. The widespread availability of the internet has facilitated access to information that was previously only available through health professionals $(6,7)$. Moreover, using the internet has increased people's knowledge and awareness about medical and health issues and has helped them have greater participation in their own health care through informed decision-making $(8,9)$.

Obtaining information from the internet is different from gathering information from traditional resources such as books $(10,11)$. Due to the complexity of the web, people with no experience of searching the internet for health information will find locating information difficult (4). Health information consumers should therefore be able to effectively process and understand online health information as they locate them. In fact, a set of skills is required to enable the use of online health information and informed participation in health care decision-making $(12,13)$. This matter is highly important regarding health issues because of the poor-quality, incorrect and confusing information available on the internet that can be harmful to the patients $(2,14,15)$.

In addition, for the proper and correct use of health information obtained from the internet, consumers require a minimum knowledge about relevant sciences and the means of identifying scientific documents and recognizing reliable resources (4). In most cases, the information retrieved from the internet is not properly understood by all groups of people. Moreover, to find eHealth information and use it for the purpose of self-care, people need proper techniques for simple and advanced information locating (4). In truth, people need eHealth literacy in order to properly use health information.

Electronic Health literacy (ehealth literacy) is defined as "the ability to search, locate, understand and use health information through electronic resources and use this knowledge to resolve healthrelated problems" (3). It aims to help people make informed decisions about healthcare using eHealth resources (3) and is considered a tool for improving health outcomes and reducing health inequities (16). Health professionals should have a proper understanding of the patients' ability to use electronic resources before recommending the use of online health information (12), and it is thus necessary to assess people's eHealth literacy.

Oral hygiene is regarded as one of the main components of physical health and well-being (17). Dental services have an excessive cost throughout the world. From dental plaque to extensive infections, oral diseases can be easily prevented through access to dental care and the effective training of the patients (18). One way of reducing dental costs is to train the public on how to prevent oral and dental diseases. In the past, providing instructions about prevention, diagnosis and treatment was exclusive to the dental team members, but the emergence of the internet made this information largely available to the general public and removed professionals' monopoly on it (19). The internet has helped patients' self-care by providing information about oral and dental health services and has a potential role in their education and empowerment. The potential benefits of informing and educating patients through the internet include the improved quality of oral and 
dental care and encouraging the acceptance of healthy behaviors, better compliance with the recommendations and the proper use of the medications. In addition, the internet does and will continue to have a central role in doctor-patient relationships (18). In dentistry, however, there is little information about patients' eHealth literacy. The present study was therefore conducted to: (A) Describe the importance and benefits of access to eHealth information resources from the perspective of dental patients; (B) Determine the eHealth literacy of dental patients; and (C) Identify the factors affecting eHealth literacy. This study hypothesizes that age and education affect eHealth literacy level.

\section{Methods}

\section{Study samples and setting}

The study setting was a private dental clinic in the west of Tehran that provided a variety of dentistry services, including oral and dental surgery, periodontics, endodontics, general dentistry, orthodontics, pediatric dentistry, restorative dentistry and prosthodontics. This descriptiveanalytical study was conducted using convenience sampling. The participants consisted of all the patients presenting to the clinic from June to September 2017. The patients younger than 18 years old and those with no experience of using the internet for obtaining health information were excluded from the study. A total of 171 adults aged 18 to 60 years participated in the study and 171 questionnaires were completed over three months. Many researchers divide adults into three age ranges, including young adults (under 40), middle adults (over 40) and older adults(over 65) (20). Therefore, the participants in this study were divided by age into over 40 age group (middle adults) and a $\leq 40$ age group (young adults). The participants were fully briefed on the study and then completed the relevant consent form. This study has been approved by ethics committee of SBMU (ethics code: IR.SBMU.RETECH.REC.1397.329)

\section{Data collection tools}

To measure eHealth literacy in the study population, the eHealth Literacy Scale (eHEALS) was used (12). This scale assesses participants' ability to properly search, locate, understand and use eHealth information. The eHEALS contains eight items scored based on a 5-point Likert scale (from 'totally disagree' $=1$ to 'totally agree' $=5$ ), with the total score ranging from 8 to 40 and higher scores indicating a higher level of eHealth literacy (12). This scale contains two supplementary items designed to assess the study population's general interest in using eHealth information. The items include the importance of access to the health information available on the internet and the usefulness of the internet in health decision-making, and are scored based on a 5point Likert scale (from 'totally useless' $=1$ to 'totally useful' $=5$ ), with the total score ranging from 2 to 10 (12). The internal consistency of the eHEALS was assessed and confirmed with a Cronbach's alpha of 0.82 , which agrees with those reported in other studies $(11,12,21)$.

\section{Data analysis}

Data were analyzed in SPSS-16. The effect of participants' age, gender and education was assessed on eHealth literacy. The qualitative variables were described using absolute and relative frequencies and the quantitative variables using the mean and standard deviation. The mean scores of eHealth literacy were compared by age and gender using the independent t-test and by education 
using the ANOVA. The difference in the scores of "Usefulness of the internet for decisionmaking", "The importance of access to eHealth information", "Ability to differentiate between quality and reliable online health information resources and poor-quality and unreliable ones", and "Adequate self-confidence in using online information for medical and health decision-making" was measured by age and gender using Mann-Whitney's test and by education using the KruskalWallis test. Spearman's correlation coefficient was also used to assess the correlation between the importance of access to health information and the usefulness of the internet for decision-making.

\section{Results:}

As shown in Table 1, the majority of the participants were female (73.7\%) and had university education $(63.2 \%)$. Also, most of them $(87.7 \%)$ were younger than age 40 (Table 1).

Table 1. Sociodemographic characteristics of study participants

\begin{tabular}{lll}
\hline Demographics & & $\mathbf{n}(\%)$ \\
\hline Gender & Female & $126(73.7)$ \\
& Male & $44(25.7)$ \\
& No response & $1(0.6)$ \\
\hline Education & High school & $63(36.8)$ \\
& graduate & $22(12.9)$ \\
& Associates degree & $53(31.0)$ \\
& Bachelor degree & $21(12.3)$ \\
& Master degree & $10(5.8)$ \\
& PhD & $2(1.2)$ \\
& No response & \\
\hline Age group & 18-40 (young & $150(87.7)$ \\
& adults) & $20(11.7)$ \\
& $>40$ (middle adults) & $1(0.6)$ \\
& No response & \\
\hline
\end{tabular}

The mean score of eHealth literacy in the participants was 30.55 ( $\mathrm{SD}=4.069)$. Given that the maximum score obtainable for this questionnaire is 40, it can be argued that the participants had a high level of eHealth literacy. Most of the participants (84.5\%) believed that the internet is useful or very useful for health decision-making and access to health information was also important or very important to most of them $(89 \%)$.

Regarding the eHEALS items, Figure 1 shows the frequency of the answers to each item. Most of the participants $(80.7 \%)$ stated that they knew how to use the information retrieved from the internet to find the answer to their health questions. The majority $(77.2 \%)$ also said that they were able to find useful health information resources on the internet (Figure 1). 


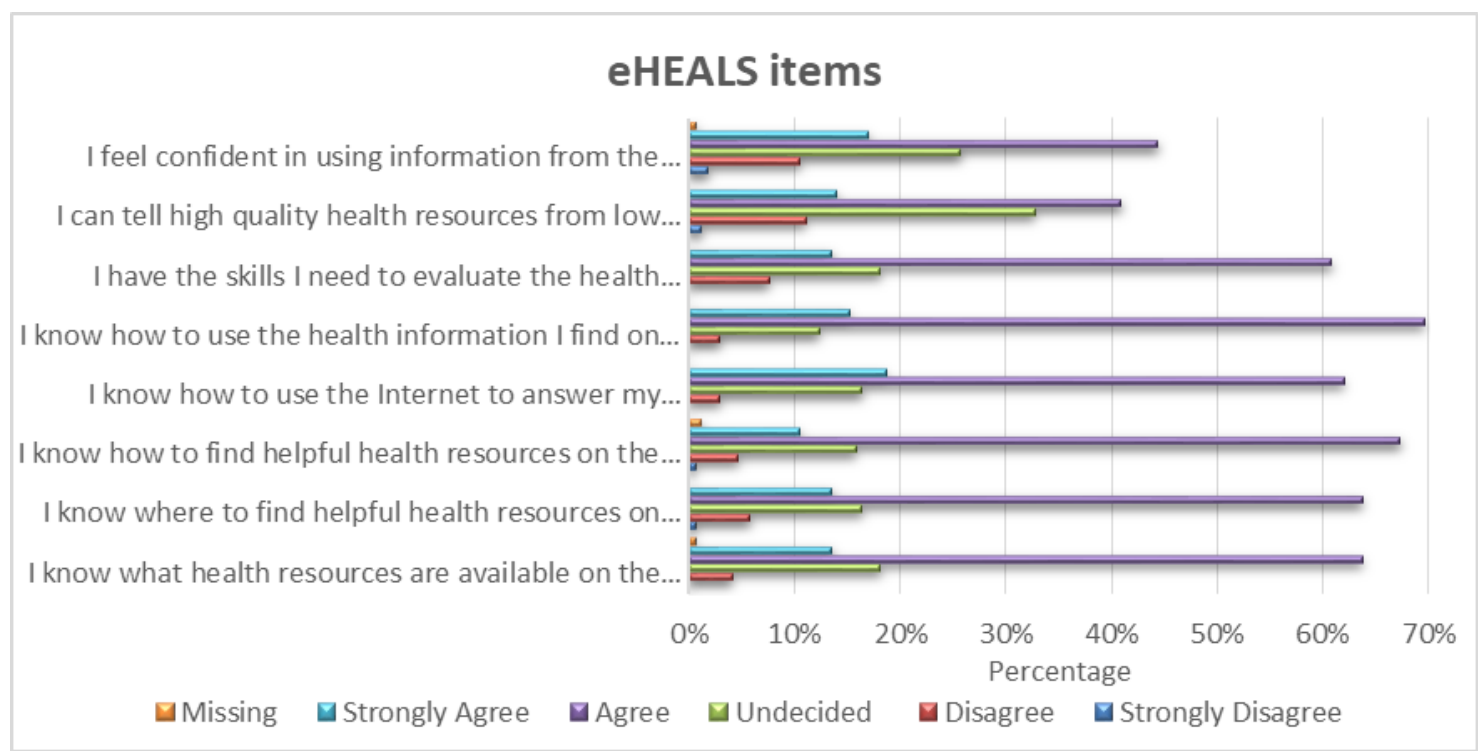

Figure 1. Responses frequencies to eHEALS items

"I can tell high quality from low quality health resources on the internet" received the lowest score $(0.908 \pm 3.56)$, indicating that the participants had the greatest difficulty in distinguishing between reliable and unreliable resources (Table 2).

Table 2. Mean and standard deviation of eHEALS items

\begin{tabular}{lcc}
\hline eHealth Literacy Scale & Mean & $\begin{array}{c}\text { Std. } \\
\text { Deviation }\end{array}$ \\
\hline I know what health resources are available on the Internet & 3.87 & .684 \\
I know where to find helpful health resources on the Internet & 3.84 & .749 \\
I know how to find helpful health resources on the Internet & 3.83 & .696 \\
I know how to use the Internet to answer my questions about health & 3.96 & .685 \\
$\begin{array}{l}\text { I know how to use the health information I find on the Internet to help } \\
\text { me }\end{array}$ & 3.97 & .627 \\
$\begin{array}{l}\text { I have the skills I need to evaluate the health resources I find on the } \\
\text { Internet }\end{array}$ & 3.80 & .764 \\
$\begin{array}{l}\text { I can tell high quality health resources from low quality health resources } \\
\text { on the Internet }\end{array}$ & 3.56 & .908 \\
$\begin{array}{l}\text { I feel confident in using information from the Internet to make health } \\
\text { decisions }\end{array}$ & 3.65 & .945 \\
\hline
\end{tabular}

The difference in eHealth literacy between the genders was also assessed, and the mean score of eHealth literacy was higher in women (30.81 44.039$)$ than in men $(29.84 \pm 4.157)$, but according to the independent $t$-test, the difference between them was not significant ( $\mathrm{t}=1.357, \mathrm{P}$-value $=0.177$ ). Mann-Whitney's test was used to measure the difference between the genders in the importance 
of access to eHealth information, the usefulness of the internet in decision-making and also the ability to differentiate between reliable and unreliable online health information resources. The results showed that although the mean scores of the importance of access to eHealth information, the usefulness of the internet in decision-making and the ability to differentiate between reliable and unreliable online health information resources were reportedly lower in men than in women, the difference between them was not statistically significant. Moreover, although the mean scores of self-confidences in using information from the internet for medical and health decision-making were reportedly higher in men than in women, the difference between them was not statistically significant (Table 3).

Table 3. The difference in Variables score between the genders

\begin{tabular}{|c|c|c|c|}
\hline \multirow{2}{*}{ Variable } & \multicolumn{2}{|c|}{ Mean score } & \multirow{2}{*}{ P-Value } \\
\hline & Female & Male & \\
\hline The importance of access to eHealth information & $4.14 \pm 0.629$ & $4.05 \pm 0.776$ & 0.541 \\
\hline The usefulness of the internet in decision-making & $4.04 \pm 0.592$ & $3.82 \pm 0.870$ & 0.140 \\
\hline $\begin{array}{l}\text { The ability to differentiate between reliable and } \\
\text { unreliable online health information resources }\end{array}$ & $3.61 \pm 0.829$ & $3.41 \pm 1.106$ & 0.239 \\
\hline $\begin{array}{l}\text { Self-confidence in using information from the } \\
\text { internet for medical and health decision-making }\end{array}$ & $3.63 \pm 0.919$ & $3.72 \pm 1.031$ & 0.551 \\
\hline
\end{tabular}

The difference in eHealth literacy was also examined in terms of education background. The results of the one-way ANOVA for eHealth literacy score between the five different education groups, including the high school graduates (30.46 \pm 3.986$)$, the associate degree holders (29.45 \pm 4.778$)$, the bachelor's degree holders, the master's degree holders $(32.00 \pm 3.715)$ and the PhD holders (30.20 \pm 4.686$)$, showed no statistically significant differences $(\mathrm{F}=1.179$, Pvalue $=0.322$ ). The results of the Kruskal-Wallis test also showed no significant differences between the education groups in terms of the importance of access to eHealth information, the usefulness of the internet for decision-making, the ability to differentiate between reliable and unreliable online health information resources and self-confidence in using information from the internet for medical and health decision-making (Table 4). 
Table 4. The difference in variables score between the educational groups

\begin{tabular}{|c|c|c|c|c|c|c|}
\hline \multirow[b]{2}{*}{ Variable } & \multicolumn{5}{|c|}{ Mean score } & \multirow[b]{2}{*}{$\begin{array}{c}\text { P- } \\
\text { Value }\end{array}$} \\
\hline & $\begin{array}{c}\text { High } \\
\text { school } \\
\text { graduate }\end{array}$ & $\begin{array}{c}\text { Associates } \\
\text { degree }\end{array}$ & $\begin{array}{c}\text { Bachelor } \\
\text { degree }\end{array}$ & $\begin{array}{c}\text { Master } \\
\text { degree }\end{array}$ & PhD & \\
\hline $\begin{array}{l}\text { The importance of access to } \\
\text { eHealth information }\end{array}$ & $3.98 \pm 0.729$ & $4.32 \pm 0.780$ & $4.19 \pm 0.557$ & $4.24 \pm 0.436$ & $3.90 \pm 0.876$ & 0.136 \\
\hline $\begin{array}{l}\text { The usefulness of the } \\
\text { internet in decision-making }\end{array}$ & $3.87 \pm 0.793$ & $4.00 \pm 0.882$ & $4.11 \pm 0.543$ & $3.95 \pm 0.498$ & $4.00 \pm 0.471$ & 0.472 \\
\hline $\begin{array}{l}\text { The ability to differentiate } \\
\text { between reliable and } \\
\text { unreliable online health } \\
\text { information resources }\end{array}$ & $3.51 \pm 0.821$ & $3.23 \pm 1.110$ & $3.68 \pm 0.872$ & $3.71 \pm 0.902$ & $3.80 \pm 1.033$ & 0.301 \\
\hline $\begin{array}{l}\text { Self-confidence in using } \\
\text { information from the } \\
\text { internet for medical and } \\
\text { health decision-making }\end{array}$ & $3.65 \pm 0.786$ & $3.23 \pm 1.193$ & $3.65 \pm 0.926$ & $3.95 \pm 0.973$ & $4.10 \pm 0.994$ & 0.70 \\
\hline
\end{tabular}

The mean score of eHealth literacy in the over-40 and 40-and-below age groups was measured using the independent $\mathrm{t}$-test. The results showed that the mean score of eHealth literacy was significantly higher in the patients younger than $40(31.03 \pm 3.736)$ compared to the patients older than $40(27.05 \pm 4.785) ;(\mathrm{t}=3.573$, P-value $=0.002)$.

Based on the results of Mann-Whitney's test, the mean score of the importance of access to eHealth information was also significantly higher in the patients younger than $40(3.80 \pm 0.616)$ compared to the patients older than $40(4.17 \pm 0.642)$. Also, the mean scores of the ability to differentiate between reliable and unreliable online health information resources was significantly higher in the patients younger than 40 (3.61 \pm 0.918$)$ compared to the patients older than $40(3.2 \pm 0.696)$, but no significant differences were observed between the two age groups in terms of the usefulness of the internet for decision-making. Although the mean scores of self-confidence in using information from the internet for decision-making was higher in the patients younger than 40 compared to those older than 40, the difference between them was not statistically significant (Table 5). 
Table 5. The difference in Variables score between the age groups

\begin{tabular}{|c|c|c|c|}
\hline \multirow{2}{*}{ Variable } & \multicolumn{2}{|c|}{ Mean score } & \multirow{2}{*}{ P-Value } \\
\hline & $18-40$ & $<40$ & \\
\hline $\begin{array}{l}\text { The importance of access to } \\
\text { eHealth information }\end{array}$ & $3.80 \pm 0.616$ & $4.17 \pm 0.642$ & 0.013 \\
\hline $\begin{array}{l}\text { The usefulness of the internet in } \\
\text { decision-making }\end{array}$ & $3.89 \pm 0.737$ & $3.99 \pm 0.675$ & 0.368 \\
\hline $\begin{array}{l}\text { The ability to differentiate } \\
\text { between reliable and unreliable } \\
\text { online health information } \\
\text { resources }\end{array}$ & $3.69 \pm 0.942$ & $3.35 \pm 0.933$ & 0.147 \\
\hline $\begin{array}{l}\text { Self-confidence in using } \\
\text { information from the internet } \\
\text { for medical and health decision- } \\
\text { making }\end{array}$ & $3.61 \pm 0.918$ & $3.20 \pm 0.696$ & 0.036 \\
\hline
\end{tabular}

Spearman's correlation test showed a significant correlation between the total score of eHealth literacy and the importance of access to eHealth information $(\mathrm{r}=0.33, \mathrm{n}=171, \mathrm{P}<0.001)$, such that a greater importance of access to eHealth information correlated with a higher eHealth literacy.

\section{Discussion}

Health promotion through self-care management is regarded as a patient empowerment tool throughout the world (22-24). Healthcare organizations and health policy-makers are both interested in involving the patients in their medical decision-making (25). Healthcare managers also consider using health information by individuals as a key factor for limiting the costs (26). Given that the internet and other new media are used by the general public for dealing with health care concerns, acquiring eHealth literacy skills appears necessary (12).

Many studies have shown the effect of eHealth literacy on health outcomes. To our knowledge, the present study is the first research to address the dental patients' eHealth literacy and also their understanding of the usefulness of eHealth information.

Previous studies have shown that more knowledgeable people use more appropriate healthcare facilities and have fewer demands for unnecessary medical tests (27). People with a high level of eHealth literacy are likely to have a high level of medical knowledge and make greater efforts to learn of and carry out screening tests compared to people with a lower literacy (28). In addition, eHealth literacy skills are important for the prevention of diseases and can help patients have a more active role in healthcare decision-making and disease management (29), since online health information empowers patients $(30,31)$. The present findings showed that dental patients have a high level of eHealth literacy. Due to their high eHealth literacy and good knowledge about preventing oral and dental diseases, the patients in this study appeared to often make greater efforts 
to preserve their oral and dental health, and in this way, they could better manage their dentistry costs. Nonetheless, regarding the patients' success rate in preventing diseases and maintaining oral and dental health, seeking the views of dentists was also mandatory.

The present study showed that access to eHealth information was important to most oral and dental patients, and they considered this information important for decision-making. Health information consumers are faced with challenges such as locating, evaluating and effectively using eHealth information for maintaining their health. Most of the participants (68\%) stated that they had adequate skills for finding useful health information resources on the internet and adequate selfconfidence for using information obtained from the internet for health decision-making (61.4\%). Nonetheless, only about half of the patients (54.9\%) stated that they had the ability to differentiate between reliable and unreliable online health information resources. People should be critical of online health information resources and should not easily accept every information they retrieve on the web (32). It is therefore essential that the patients receive support and training for eHealth literacy from healthcare professionals, especially regarding the quality of health information, so that they can properly evaluate the retrieved information.

The present study showed that access to eHealth information and the usefulness of the internet for decision-making had greater importance for patients with higher eHealth literacy. This finding may be due to the fact that people with high eHealth literacy have the skills needed for obtaining health information from the internet and therefore consider using this medium as one of the most important and useful resources for obtaining health information.

Most of the participants (69\%) stated that they knew how to use eHealth information to their benefit. The results of a study conducted by Park (2015) on nursing students in South Korea were consistent with this finding (29).

In a study on the effect of the internet on dentistry, all the dentists believed that the Internet is a useful resource for the patients to obtain oral and dental health information, but the patients are likely to wrongly interpret this information (33). Dentists' active support to help patients properly understand online oral and dental information therefore seems absolutely necessary. Conversations that patients have with the doctors about their health information-seeking behaviors can help prevent the harmful and costly consequences of delayed treatment or risks caused by wrong actions or wrong interpretations of information by the patients $(34,35)$.

Most of the participants (54.9\%) stated that they were confident about recognizing the quality of online health information. A study conducted by the Pew Internet and American Life Project on people who use the internet to find information showed that $72 \%$ trust a large part of the information they retrieve online (9). Patients should be familiar with the limitations of information resources in order to be able to critically assess online health information and effectively cooperate with health professionals in health decision-making $(36,37)$. Some studies have shown that patients trust the information they retrieve online and only half of them consult with their doctors about the information obtained this way (38-40). In their search for health information on the internet, people may come across wrong, faulty and even misleading information, and it is necessary for them to recognize the accuracy and credibility of this information. Given that the participants of this study believed that they were able to differentiate between reliable and unreliable content, it is necessary to know on what basis they place their analysis of the accuracy and rigor of this information. Since 
the initial assessment of online information is affected by the website design, such that more amateur people trust more attractive websites and consider unappealing and poorly-designed websites as unreliable $(41,42)$, it is important for dental patients to know that the proper understanding of virtual health information requires professional knowledge and a thorough consultation with the doctor (43). Dentists should also be prepared to discuss the issues raised by their patients about the information they have retrieved online.

One problem is that the lay public (i.e. the non-experts) may not be able to properly assess the quality and accuracy of online health information due to their lack of training and skills. The present study showed that "the ability to differentiate between quality and reliable online health information resources and unreliable ones" was the biggest problem for dental patients. This finding agrees with the results obtained in a study on eHealth literacy in COPD patients (44). It is therefore necessary for healthcare professionals to warn their patients about the risks of the improper assessment of the validity of online health information to reduce the destructive effects of using incorrect information by the patients.

\section{The assessment of eHealth literacy-related variables}

These findings present the factors associated with dental patients' eHealth literacy. In this study, the sociological variables including gender and education had no significant relationship with eHealth literacy in oral and dental patients. As for age, the participants were divided into a 18-40 and an over-40 age group, and the eHealth literacy of the younger dental patients was assumed and later proven to be higher, and age was found to be a factor affecting eHealth literacy ( $\mathrm{t}=3.573$, Pvalue $=0.002)$, as consistent with the results of other studies $(6,28,45,46)$. Also, the middle adult patients reported less ability in recognizing the quality of information retrieved online compared to the younger adult patients, which agrees with the results of other studies $(6,47)$. This finding may be due to the fact that young adults have more experience using the internet compared to middle adults and have better access to digital media (7). Dentists should therefore be aware that not all patients have the same knowledge for using eHealth resources and younger patients have higher eHealth literacy. It is therefore important to take note of the patients' age when advising them to use the internet and to encourage them to consult with their dentists about eHealth information.

Another study conducted on dental patients' information-seeking behavior showed that those with higher education display greater motivation for using online information resources (48). People with higher education levels were thus expected to be more capable of recognizing quality and reliable health information resources from poor-quality and unreliable ones, but the results of the Kruskal-Wallis test showed no significant differences between the different education groups in terms of this ability (P-value $=0.301)$. This issue may be due to the higher knowledge of educated people about the difficulty of recognizing the quality of online health information resources, which must have made them report less ability.

Education level affects people's internet access and subsequently online search for health information (49). The present study therefore assumed the dental patients' eHealth literacy to be related to their education level, but in line with the results of other studies $(28,48)$ no significant relationships were observed between education level and the score of eHealth literacy. A study measuring eHealth literacy in cardiovascular patients showed that patients with lower education 
have lower eHealth literacy (50). Further studies are required to find a more definitive relationship between eHealth literacy and education level.

In the present study, greater confidence in using the internet to get health information for decisionmaking was associated with a higher eHealth literacy score. It should be noted, however, that people who search the web for medical information are mainly those who seek further (or alternative) information about the treatment of a particular disease that answers their health-related questions and helps them make informed decisions (51). Nonetheless, this objective is not always easily accomplished, since people who search the web for medical information often encounter contradictory evidence (52).

Health professionals are concerned about people's use of the internet to identify and treat diseases, because, in the absence of consultation with doctors, patients may interpret or use online information wrongly $(53,54)$. Patients also search for further information about their doctors' advices (55); however, they should accept the fact that there are various alternative treatments and interpretations of the symptoms of diseases and even different interpretations of pathophysiologic test results (56).

Some studies suggest that women use the internet for obtaining health information more than men (57) and often decide to visit a doctor after they have retrieved some health information online (55). Given this tendency and the fact that obtaining and properly using eHealth information requires eHealth literacy, women are expected to have greater eHealth literacy than men in the current research. The present study therefore assumed female dental patients to have greater eHealth literacy than male patients, but the results showed no significant differences between the genders in terms of the eHealth literacy level, which agrees with the results of previous studies $(6,45,58)$. A study conducted by Aponte (2017), however, showed that men's health literacy is much lower than women's (59). Further studies are therefore required on the health literacy of men and women. In addition, the present findings showed that access to online health information is more important to women. It is therefore necessary to warn female patients about the risks of information retrieved from the internet to enable them to use this information in an informed and correct manner.

Doctors also use the internet as a supplemental tool to search for medical information (32). Electronic health literacy is therefore also needed by health professionals, including dentists, to enable them to help their patients obtain more updated, reliable and quality information highlighted.

\section{Conclusions}

This study showed that dental patients have a high level of eHealth literacy. It is imperative though to assess the actual eHealth literacy of these patients to reach a definitive understanding. Using online health information was important to most oral and dental patients. Dental clinics can use the results of this study to publish information on their websites about different oral and dental diseases and the means of their prevention and treatment, so that people can easily access the information they need about the services provided by these centers and decide about their use. 
Women had a greater interest in obtaining health information and found it more important compared to men. Since women have a key role in maintaining their own and their family's health, this issue may be interesting and beneficial to institutions such as women's health awareness campaigns, especially oral and dental health campaigns. By publishing health information on their own and other reliable websites, these institutions can have a key role in maintaining community's health, particularly women's health.

Determining eHealth literacy in oral and dental patients leads to a better understanding of their problems in health decision-making. Further empowering oral and dental patients requires more comprehensive studies on the use of the internet and medical services.

\section{Limitations}

Our findings are hampered by some limitations. At first, our study measured the eHealth literacy of patients based on their self-reports and not actual performance or record of Internet use. Therefore, their actual online information usage or their actual performance has not been identified. Thus, more studies that measure actual use and skill are required. The other limitation is related to the sampling frame. In this study convenience sampling was used because of ease of access to patients. Other patients who referred in other period of time may have been less or more eHealth literate. Moreover, the study of eHealth literacy in different contexts can get different results.

\section{Acknowledgements}

The authors would like to thank professor Yasser Khazaal and appreciate his kind supports for this study.

\section{Financial Disclosure}

This article is extracted from the research project (code 14598) which is funded by the School of Allied Medical Sciences, Shahid Beheshti University of Medical Sciences.

\section{References}

1. Madden M, Fox S. Finding Answers Online in Sickness and in Health | Pew Research Center. Retrieved 01/08/08 from http://www. pewinternet. org/PPF/r/183/report_display. asp; 2006.

2. Alba-Ruiz R, Bermúdez-Tamayo C, Pernett JJ, Garcia-Gutierrez JF, Cózar-Olmo JM, et al. 2013. Adapting the Content of Cancer Web Sites to the Information Needs of Patients: Reliability and Readability. Telemed $J$ E Health. 19(12), 956-66. PubMed https://doi.org/10.1089/tmj.2013.0050

3. Norman CD, Skinner HA. 2006. eHealth literacy: essential skills for consumer health in a networked world. J Med Internet Res. 8(2), e9. PubMed https://doi.org/10.2196/jmir.8.2.e9 
4. Hanik B, Stellefson M. 2011. E-Health Literacy Competencies among Undergraduate Health Education Students : A Preliminary Study [Internet]. Int Electron J Health Educ. 14, 46-58. http://www.eric.ed.gov/ERICWebPortal/detail?accno=EJ946322.

5. Kommalage M, Thabrew A. 2008. The use of websites for disseminating health information in developing countries: an experience from Sri Lanka. Int J Electron Healthc. 4(3/4), 32738. PubMed https://doi.org/10.1504/IJEH.2008.022669

6. Tennant B, Stellefson M, Dodd V, Chaney B, Chaney D, et al. 2015. eHealth literacy and Web 2.0 health information seeking behaviors among baby boomers and older adults. $J$ Med Internet Res. 17(3), e70. PubMed https://doi.org/10.2196/jmir.3992

7. Percheski C, Hargittai E. 2011. Health Information-Seeking in the Digital Age. J Am Coll Health. 59(5), 379-86. PubMed https://doi.org/10.1080/07448481.2010.513406

8. Rice RE. 2006. Influences, usage, and outcomes of Internet health information searching: multivariate results from the Pew surveys. Int J Med Inform. 75(1), 8-28. PubMed https://doi.org/10.1016/j.ijmedinf.2005.07.032

9. Shedlosky-Shoemaker R, Sturm AC, Saleem M, Kelly KM. 2009. Tools for assessing readability and quality of health-related Web sites. J Genet Couns. 18(1), 49-59. PubMed https://doi.org/10.1007/s10897-008-9181-0

10. Brandtweiner R, Donat E, Kerschbaum J. 2010. How to become a sophisticated user: a twodimensional approach to e-literacy. New Media Soc. 12(5), 813-33. https://doi.org/10.1177/1461444809349577

11. van der Vaart R, van Deursen AJAM, Drossaert CHC, Taal E, van Dijk JAMG, et al. 2011. Does the eHealth Literacy Scale (eHEALS) measure what it intends to measure? Validation of a Dutch version of the eHEALS in two adult populations. J Med Internet Res. 13(4), e86. PubMed https://doi.org/10.2196/jmir.1840

12. Norman CD, Skinner HA. 2006. eHEALS: The eHealth Literacy Scale. J Med Internet Res. 8(4). PubMed https://doi.org/10.2196/jmir.8.4.e27

13. Hove T, Paek H-J, Isaacson T. 2011. Using Adolescent eHealth Literacy To Weigh Trust in Commercial Web Sites. J Advert Res. 51(3). https://doi.org/10.2501/JAR-51-3-524-537

14. Rahmatizadeh S, Valizadeh-Haghi S. 2018. Evaluating the trustworthiness of consumeroriented health websites on diabetes. Libr Philos Pract. 4

15. Valizadeh-Haghi S, Rahmatizadeh S. 2018. Evaluation of the Quality and Accessibility of Available Websites on Kidney Transplantation. Urol J. 5(5), 261-265 PubMed

16. Wu AD, Begoray DL, Macdonald M, Wharf Higgins J, Frankish J, et al. 2010. Developing and evaluating a relevant and feasible instrument for measuring health literacy of Canadian high school students. Health Promot Int. 25(4), 444-52. PubMed https://doi.org/10.1093/heapro/daq032 
17. Mirza RD, Phelan M, Wulff-Cochrane V. 2001. Oral health of psychiatric in-patients. Psychiatr Bull. 25, 143-45. https://doi.org/10.1192/pb.25.4.143

18. Assocation NG. The Role of Dental Hygienists in Providing Access to Oral Health Care [Internet]. National Governors Assocation. 2014 [cited 2018 Nov 10]. Available from: https://classic.nga.org/files/live/sites/NGA/files/pdf/2014/1401DentalHealthCare.pdf

19. Harris CE, Chestnutt IG. 2005. The use of the Internet to access oral health-related information by patients attending dental hygiene clinics. Int J Dent Hyg. 3(2), 70-73. PubMed https://doi.org/10.1111/j.1601-5037.2005.00129.x

20. Sana JDL, Martha S, eds. Encyclopedia of Aging and Public Health. Springer; 2008.

21. Bazm S, Mirzaei M, Fallahzadeh H, Bazm R. 2016. Validity and Reliability of the Iranian Version of eHealth Literacy Scale. Journals Community Heal Res. 5(2), 121-30.

22. Bianco A, Zucco R, Nobile CGA, Pileggi C, Pavia M. 2013. Parents seeking health-Related information on the internet: Cross-sectional study. J Med Internet Res. 15(9). PubMed https://doi.org/10.2196/jmir.2752

23. García-Goñi M, Hernández-Quevedo C, Nuño-Solinís R, Paolucci F. 2012. Pathways towards chronic care-focused healthcare systems: Evidence from Spain. Health Policy. 108(2-3), 23645. PubMed https://doi.org/10.1016/j.healthpol.2012.09.014

24. Lorig K, Ritter PL, Plant K, Laurent DD, Kelly P, et al. The South Australia Health Chronic Disease Self-Management Internet Trial. Heal Educ Behav [Internet]. 2013;40(1):67-77. Available from: http://journals.sagepub.com/doi/10.1177/1090198112436969

25. Hack TF, Degner LF, Parker PA, Baile W, Brundage M, et al. 2005. The communication goals and needs of cancer patients: A review. Psychooncology. 14(10), 831-45. PubMed https://doi.org/10.1002/pon.949

26. Bunn MD. 1994. Aspects of Consumer Search for Health Information. Health Mark Q. 11(34), 75-98. PubMed https://doi.org/10.1300/J026v11n03_08

27. Macias W, Lewis L, Shankar V. 2004. Dr. Mom and Dr. Web: A qualitative analysis of women's use of health information on the web. J Interact Advert. 17(1), 65-78. https://doi.org/10.1080/15252019.2004.10722083

28. Mitsutake S, Shibata A, Ishii K, Oka K. 2012. Association of ehealth literacy with colorectal cancer knowledge and screening practice among internet users in Japan. J Med Internet Res. 14(6). PubMed https://doi.org/10.2196/jmir.1927

29. Park H, Lee E. 2015. Self-reported eHealth literacy among undergraduate nursing students in South Korea: A pilot study. Nurse Educ Today. 35(2), 408-13. PubMed https://doi.org/10.1016/j.nedt.2014.10.022 
30. Sillence E, Briggs P, Harris PR, Fishwick L. 2007. How do patients evaluate and make use of online health information? Soc Sci Med. 64(9), 1853-62. PubMed https://doi.org/10.1016/j.socscimed.2007.01.012

31. Xie B. 2009. Older adults' health information wants in the internet age: Implications for patient-provider relationships. $J$ Health Commun. 14(6), 510-24. PubMed https://doi.org/10.1080/10810730903089614

32. Chan J, Leung A, Chiang VCL, Li HCW, Wong EM, et al. A pilot project to build e-health literacy among university students in Hong Kong. Position Prof Tenth Int Congr Med Librariansh. 2009;1-15.

33. Chestnutt IG, Reynolds K. 2006. Perceptions of how the Internet has impacted on dentistry. Br Dent J. 200(3), 161-65. PubMed https://doi.org/10.1038/sj.bdj.4813195

34. Lau F, Price M, Keshavjee K. 2011. From Benefits Evaluation to Clinical Adoption: Making Sense of Health Information System Success in Canada [Internet]. Healthc Q 14(1), 39-45. http://www.longwoods.com/content/22157.PubMedhttps://doi.org/10.12927/hcq.2011.22157

35. Nijland N, Van Gemert-Pijnen J, Boer H, Steehouder MF, Seydel ER. 2008. Evaluation of internet-based technology for supporting self-care: Problems encountered by patients and caregivers when using self-care applications. J Med Internet Res. 10(2). PubMed https://doi.org/10.2196/jmir.957

36. Anderson RM, Funnell MM. 2010. Patient empowerment: Myths and misconceptions. Patient Educ Couns. 79(3), 277-82. PubMed https://doi.org/10.1016/j.pec.2009.07.025

37. Aujoulat I, D'Hoore W, Deccache A. 2007. Patient empowerment in theory and practice: Polysemy or cacophony? Patient Educ Couns. 66(1), 13-20. PubMed https://doi.org/10.1016/j.pec.2006.09.008

38. Janatian S, Mojiri S, Shahrzadi L, Zhedi R, Ashrafi Rizi H. 2014. Evaluating the Quality of Persian Depression Websites Based On Webmedqual Scale. J Heal Adm. 17(55), 89-98.

39. Kaicker J, Debono VB, Dang W, Buckley N, Thabane L. 2010. Assessment of the quality and variability of health information on chronic pain websites using the DISCERN instrument. BMC Med. 8(1), 59. PubMed https://doi.org/10.1186/1741-7015-8-59

40. Hayati Z, Dehghan L. 2012. A Survey of Acquaintance and Application of Web Information Quality Criteria: A Case Study of Post-Graduate Students in Shiraz University. Inf Process Manage. 27(4), 1011-31.

41. Sillence E, Briggs P, Harris P, Fishwick L. 2007. Health websites that people can trust-the case of hypertension. Interact Comput. 19(1), 32-42.

https://doi.org/10.1016/j.intcom.2006.07.009 
42. Fogg BJ, Soohoo C, Danielson DR, Marable L, Stanford J, et al. How do users evaluate the credibility of Web sites?: a study with over 2,500 participants. In: Proceedings of the 2003 conference on Designing for user experiences. ACM; 2003. p. 1-15.

43. Broom A. 2005. Virtually he@1thy: the impact of internet use on disease experience and the doctor-patient relationship. Qual Health Res. 15(3), 325-45. PubMed https://doi.org/10.1177/1049732304272916

44. Stellefson ML, Shuster JJ, Chaney BH, Paige SR, Alber JM, et al. 2018. Web-based Health Information Seeking and eHealth Literacy among Patients Living with Chronic Obstructive Pulmonary Disease (COPD). Health Commun. 33(12), 1410-1424. PubMed

45. Neter E, Brainin E. eHealth Literacy: Extending the Digital Divide to the Realm of Health Information. J Med Internet Res. 27.01.2012. 2012;14(1):e19.

46. Zibrik L, Khan S, Bangar N, Stacy E, Novak Lauscher H, et al. 2015. Patient and community centered eHealth: Exploring eHealth barriers and facilitators for chronic disease selfmanagement within British Columbia's immigrant Chinese and Punjabi seniors. Health Policy Technol. 4(4), 348-56. https://doi.org/10.1016/j.hlpt.2015.08.002

47. Manafò E, Wong S. 2012. Assessing the eHealth Literacy Skills of Older Adults: A Preliminary Study. J Consum Health Internet. 16(4), 369-81.

https://doi.org/10.1080/15398285.2012.701163

48. Hanna K, Sambrook P, Armfield JM, Brennan DS. Internet use, online information seeking and knowledge among third molar patients attending public dental services. Aust Dent $\mathbf{J}$ [Internet]. 2017; Available from: http://www.ncbi.nlm.nih.gov/pubmed/28241385\%0Ahttp://doi.wiley.com/10.1111/adj.1250 9

49. How do those who don't search for health information online differ from those who do? | Pew Research Center [Internet]. 2011. Available from: http://www.pewresearch.org/2011/12/13/how-do-those-who-dont-search-for-healthinformation-online-differ-from-those-who-do/50. Richtering SS, Hyun K, Neubeck L, Coorey G, Chalmers J, et al. eHealth Literacy: Predictors in a Population With Moderate-toHigh Cardiovascular Risk. JMIR Hum Factors [Internet]. 2017;4(1):e4. Available from: http://humanfactors.jmir.org/2017/1/e4/

51. Fox S, Rainie L, Horrigan J, Lenhart A, Spooner T, et al. The online health care revolution: How the Web helps Americans take better care of themselves. Pew Internet \& American Life Project. 2000.

52. Eysenbach G. 2003. The impact of the internet on cancer outcomes. CA Cancer J Clin. 53(6), 356-71. PubMed https://doi.org/10.3322/canjclin.53.6.356

53. Scanfeld D, Scanfeld V, Larson EL. 2010. Dissemination of health information through social networks: Twitter and antibiotics. Am J Infect Control. 38(3), 182-88. PubMed https://doi.org/10.1016/j.ajic.2009.11.004 
54. Antheunis ML, Tates K, Nieboer TE. 2013. Patients' and health professionals' use of social media in health care: Motives, barriers and expectations. Patient Educ Couns. 92(3), 426-31. PubMed https://doi.org/10.1016/j.pec.2013.06.020

55. Bidmon S, Terlutter R. 2015. Gender differences in searching for health information on the internet and the virtual patient-physician relationship in Germany: Exploratory results on how men and women differ and why. $J$ Med Internet Res. 17(6), e156. PubMed https://doi.org/10.2196/jmir.4127

56. Kienhues D, Stadtler M, Bromme R. 2011. Dealing with conflicting or consistent medical information on the web: When expert information breeds laypersons' doubts about experts. Learn Instr. 21(2), 193-204. https://doi.org/10.1016/j.learninstruc.2010.02.004

57. Terlutter R, Bidmon S, Röttl J. 2014. Who uses physician-rating websites? differences in sociodemographic variables, psychographic variables, and health status of users and nonusers of physician-rating websites. J Med Internet Res. 16(3). $\underline{\text { PubMed }}$ https://doi.org/10.2196/jmir.3145

58. Robb M, Shellenbarger T. 2014. Influential factors and perceptions of eHealth literacy among undergraduate college students [Internet]. Online J Nurs Inform. 18(3), 1. http://www.himss.org/influential-factors-and-perceptions-ehealth-literacy-amongundergraduate-college-students.

59. Aponte J, Nokes KM. 2017. Electronic health literacy of older Hispanics with diabetes. Health Promot Int. 32(3), 482-89. PubMed https://doi.org/10.1093/heapro/dav112 